\title{
|||||||||||||||||||||||||||||||||||||||||||||||||||||||||||||||||||||.
}

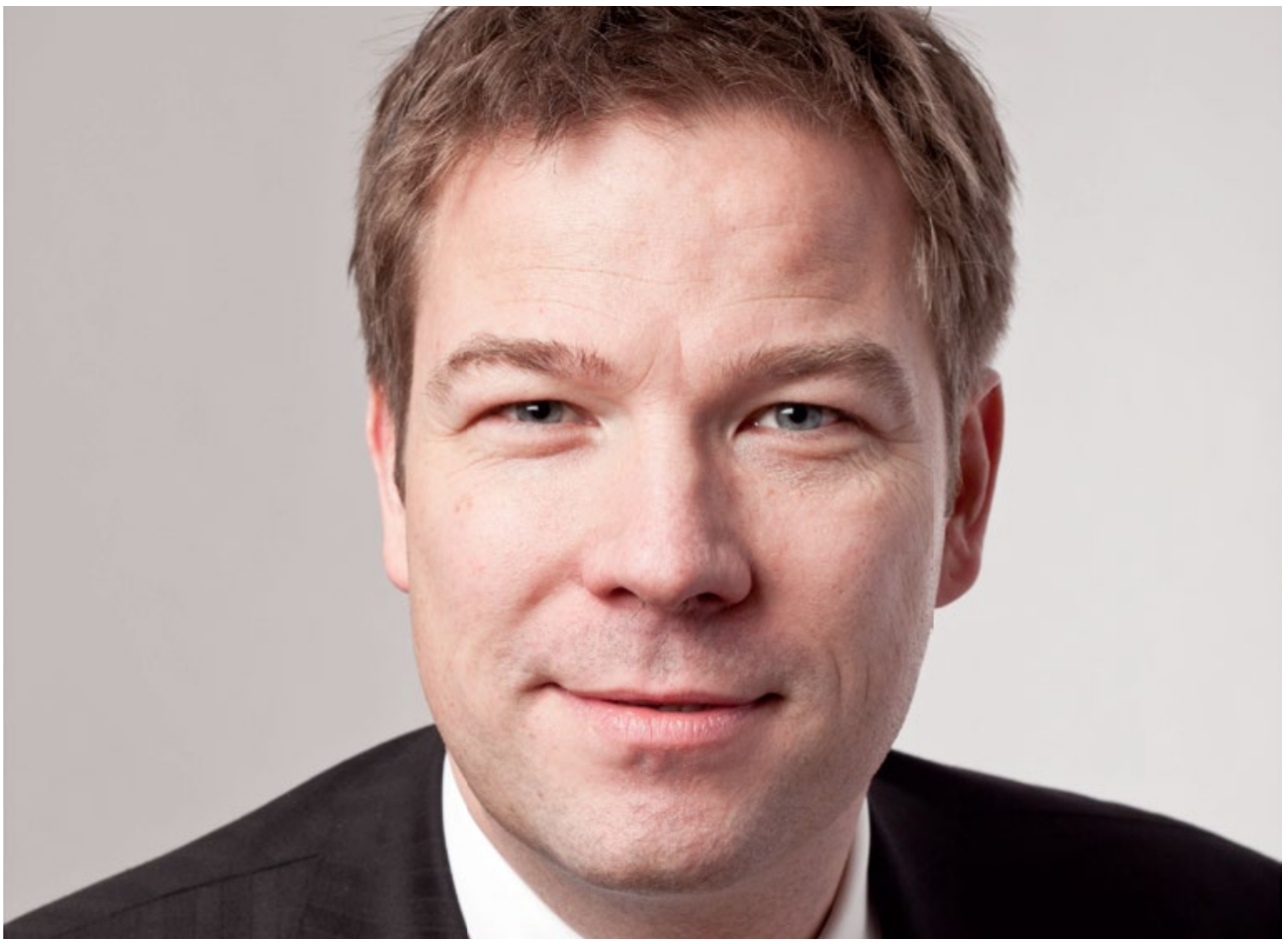

DR. OLIVER BERTRAM

Rechtsanwalt und Partner,

Wirtschaftskanzlei Taylor Wessing

\section{ÜBERLASSUNG AUF DEM PRÜFSTAND}

Dem Einsatz von Engineering-Dienstleistern in der Automobilindustrie stehen nach der Ankündigung der Bundesregierung große Veränderungen bevor. Die Abgrenzung zwischen Werkoder Dienstverträgen und einer Arbeitnehmerüberlassung (ANÜ) soll gesetzlich strenger normiert werden. Hierbei soll dem Auftraggeber insbesondere die Möglichkeit entzogen werden, sich durch eine Erlaubnis zur Arbeitnehmerüberlassung abzusichern. Scheinwerkverträge oder -dienstverträge führen so zukünftig dazu, dass ein beim Kunden eingesetzter Ingenieur zu dessen Arbeitnehmer wird. Der Auftraggeber haftet demnach für Lohn sowie Sozialversicherungsbeiträge - ein großes Risiko, da die Nichtabführung von Sozialversicherungsbeiträgen eine Straftat darstellen kann.

Parallel beabsichtigt die Große Koalition das Arbeitnehmerüberlassungsrecht restriktiver zu gestalten. Die maximale Entleihdauer soll, mit tariflichen Öffnungsklauseln, auf 18 Monate begrenzt werden. Ab dem neunten Monat soll bereits das „Equal pay“-Prinzip gelten. Entliehene Arbeitnehmer wären danach so zu bezahlen wie ein vergleichbarer Arbeitnehmer des Entleihers.

Die aktuelle Praxis der Beauftragung von Entwicklungsdienstleistungen wird somit zukünftig kaum zu halten sein. Pauschalierte Dienstleistungsverträge für Externe ohne konkrete Leistungsbeschreibung werden ebenso wie der arbeitsorganisatorisch integrierte Einsatz von Freelancern zum Risikofaktor. Eine ANÜ wäre die Alternative, doch diese ist mit
18 Monaten Entleihdauer für Entwicklungsabteilungen zu knapp bemessen. Da in der Automobilindustrie die meisten Projekte nicht von Beginn an über Werkverträge vergeben werden können - dem stehen Entwicklungsprozesse und die Sicherung der Kerneigenleistung entgegen -, ist die interne Nutzung externer Fachleute unverzichtbar. Von den Entwicklungsabteilungen wird damit ein Spagat verlangt: Sie sollen unter Kostendruck Entwicklungszyklen optimieren; gleichzeitig fördern Gesetzgeber und Rechtsprechung die Desintegration der Prozesse. So geraten Entwicklungs- und Einkaufsabteilung in einen internen Konflikt, da die einen aus rechtlichen Gründen nicht beschaffen können, was andere dringend brauchen.

Sind valide Lastenhefte und eine eindeutige Abgrenzung möglich, wird man einen Teil der Fremdleistungen in Gewerke überführen können. In Grauzonen müssen die Mitarbeiter in ANÜ-Einsätze überführt werden. Die Dienstleister müssen eine Erlaubnis dazu besitzen und die Mitarbeiter tarifgebunden sein. Insbesondere für Entwicklungsarbeiten wird man nach einer integrierten Phase der Mitarbeit in der weiteren Projektumsetzung auf eine Fremdbeauftragung im Dienst- oder Werkvertrag umstellen können. Es kommt also darauf an, intelligente Kombinationen aus ANÜ, selbstständigen Dienstverträgen und Gewerken zu finden, um Entwicklungsprozesse rechtlich und kostenseitig abzusichern. Dabei müssen alle Projekte mit Fremdpersonaleinsatz auf den Prüfstand. 